\title{
A Multiple Objective Search Process for Management Using a Transfer Pricing Example
}

\author{
Mark Cecchini ${ }^{1}$, Robert Leitch ${ }^{1} \&$ Caroline Strobel ${ }^{1}$ \\ ${ }^{1}$ School of Accounting, Darla Moore School of Business, University of South Carolina, USA \\ Correspondence: Mark Cecchini, School of Accounting, Darla Moore School of Business, University of South \\ Carolina, 1705 College Street, Columbia, SC, 29208. USA. Tel: 1-803-777-6643. E-mail: \\ cecchini@moore.sc.edu
}

Received: July 10, 2013

Accepted: October 11, $2013 \quad$ Online Published: October 15, 2013

doi:10.5539/ijbm.v8n21p89

URL: http://dx.doi.org/10.5539/ijbm.v8n21p89

\begin{abstract}
Accounting managers of the multinational enterprise are responsible for budgeting and planning for a wide array of often conflicting objectives and constraints. Effective decision tools that support management in understanding tradeoffs between objectives of the budget process are invaluable. We explain the background of and then illustrate an interactive search process for solving complex multiple objective problems. The methodology we employ is a variant of multiple objective linear programming (MOLP) called the Combined Tchebycheff/Aspiration method. This method enables management to direct their search for a satisfactory or optimal solution set as they discover what is feasible and tradeoffs among conflicting objectives. This is in contrast to goal programming where weights on objectives are determined beforehand. We illustrate the solution method on the transfer pricing problem. The result is a search process that uses a mathematically rigorous procedure to structure a complex problem, while including management feedback throughout the solution process.
\end{abstract}

Keywords: multiple objective linear programming, interactive search process, transfer pricing, multinational enterprise

\section{Introduction}

Managerial accountants rarely have the luxury of dealing with single objective functions. Multiple objective linear programming (MOLP) allows researchers and practitioners to directly consider multiple objectives when solving management accounting problems, whereas linear programming or goal programming methods are limited to single objectives or the minimization of the sum of deviations from multiple goals. Goal programming requires an a priori weighting oneach of the objectives, effectively converting multiple objectives into a weighted single objective linear program. The problem is that in most business cases, there are always tradeoffs as to which objectives are more important. This problem is especially complex in reality because these tradeoffs are generally unknown at the beginning of the search process for a solution and objectives are often correlated either positively or negatively and may even conflict. Real problems may be very large and involve many variables making it even more difficult to specify goals, weights and tradeoffs a priori. Moreover, weights presuppose a simple utility function, which may be difficult to articulate given the complexity of the problem. As a result, the conventional methods of simply maximizing one objective or using goal programming to weight many objectives may be lacking when dealing with multiple correlated and conflicting objectives. We illustrate the merits of MOLP and compare it with linear programming using a single objective and goal programming using multiple objectives. We use the multinational transfer pricing problem to illustrate the value of the MOLP search process.

MOLP generalizes the mathematics in linear programming to a multiple objective setting, allowing the manager to gain insights into the tradeoffs between the objectives. Because these tradeoffs are unknowna priori, MOLP presupposes an unclear utility function for management at the outset (Note 1). MOLP allows management to derive their utility in terms of the goals they assess and various tradeoffs throughout the search process, ultimately finding a satisfactory solution. The MOLP method proposed and illustrated here utilizes an iterative search process, returning results from an increasingly smaller neighborhood surrounding the most desired solution at each iteration. The MOLP procedure presented here also allows management to direct the search in a 
different direction more in line with their utility if theydo not like the results they see. The process concludes when management is satisfied that they are as close as possible to a set of results that resemble their derived utility.

We illustrate this method using a Multinational Enterprise (MNE) transfer price problem (Note 2). MNEs are formed to take advantage of global market imperfections and managing transfer prices is one way that managers profit from such imperfections. Transfer pricing represents one of the most important items on the agenda of MNE tax managers, according to a recent survey of 850 MNEs (Ernst \& Young 2007). However, determining optimal transfer prices for a multinational firm is a complex problem. One of the problems encountered in determining a satisfactory or optimal set of MNE transfer prices is that they tend to serve multiple objectives; such as the maximization of global profit, which is tantamount to the minimization of global taxes, the maximization of subsidiary divisional profits to achieve management control objectives, and reduction of economic or sociopolitical risks. These objectives often conflict, making the MNE transfer pricing problem especially complex. We select several transfer pricingobjectives that are correlated and conflict to illustrate the MOLP solution procedure. We consider an environment where the tax rates are different for each country. We select the goal of maximizing total firm profit, which is commonly used in single objective linear programming solutions to transfer pricing problems. We also select correlated goals of maximizing the profit for each division. These may conflict since increasing the profit of one division may come at the cost of another division. We also consider a managerial objective of treating each division equitablyin terms of the distribution of profit. Again this may conflict with maximizing each division's profit and maximizing total firm profit. We also consider a socio political objective of moving money out of a country, assumingleaving money in that county represents a risk. This goal may conflict with the other objectives as well. Moreover, transfer prices and dividend repatriation (moving money out of a country) may be constrained by tax authorities and government regulations.

The question is, how can management accountants, as they support management decision-making, search among conflicting objectives to find a satisfactory (or optimal) solution when management would be hard pressed to clearly specify their preferences a priori, due to lack of information on the trade-offs among the objectives. To have more complete information the manager must understand how objectives interact and what tradeoffs are feasible. Thus, researchers and practitioners need a solution procedure to help management understand tradeoffs and objective feasibility to derive and ultimately satisfy their utility functions.

MOLP provides a structure to the MNE transfer pricing problem. Management can learn enough through several iterations of the model to infer their ill-defined utility from a mix of feasible multinational transfer pricing objectives. The importance of any one objective is then determined after feedback on the feasibility of trade-offs among competing objectives (Note 3). Once management learns something about what is feasible and what tradeoffs are possible they can then direct the search among feasible sets of objectives to find a satisfactory solutionto the problem.

Vastly different measurement scales may compound the difficulty in assessing these tradeoffs. Thus, in a MNE transfer pricing problem, objective weights may be better derived interactively throughout the decision-making process using an adaptive system rather than determined a priori (e.g., Morse 1978; Zeleny 1983; Steuer 1986), as is required for goal programming (e.g., Lin \& O'Leary 1993). Once management learns something about what is feasible and what tradeoffs are possible they may want to actually direct the search among feasible sets of objectives; that is, take an active role in directing the search process (Note 4).

Our process aids in framing the problem to focusmanagement's cognitive process onresults. At the conclusion of the search process the objective results are then easily transformed into the actions necessary to achieve results. In this transfer pricing example the search process can be used in a number of ways including: (1) determination of optimal or satisfactory transfer prices based on management preferences for various objectives, (2) assessment of tradeoffs among objectives as divisions negotiate transfer prices, and (3) use of the model to plan a MNE compliance strategy.

In summary, multiple-objective management accounting problems, such as the MNE transfer pricing problem, have characteristics that make them very difficult to solve. A MOLP search process is proposed in this paper as a way of helping management assess possible optimal solutions. The rest of the paper is organized as follows. We briefly explain the objectives and constraints that affect MNE transfer pricing in the next section. In the third section we explain MOLP and the search process. In the fourth section we formulate a transfer pricing problem and illustrate the solution methodology, comparing our results to a single objective linear program and a goal program. And finally, in the fifth section we concludeour study. 


\section{The Transfer Pricing Problem}

MNEs are formed to take advantage of the economic and sociopolitical factors that give rise to global market imperfections. These imperfectionsare due to differences in the availability of labor, capital, materials, tax structure, intermediate and final markets, reinvestment and capital flow requirements, as well as economic and socio-political risks. A major challenge for MNEs is to determine the optimal transfer pricing scheme to maximize their objectives relative to these market imperfections and constraints. We select this very complex problem to illustrate the advantages of using the MOLP search process.

The most common goal of MNE transfer pricing is the maximization of global profit or the minimization of taxes. However, there are many other economic and managerial factors to consider.

The maximization of foreign subsidiary (division) performance and profit is another important objective. This is particularly important if the MNE is organized to encourage divisional managers to act as though they are independent entities, via profit or investment centers. Transfer pricing affects the evaluation of these subsidiaries and their managers, and thus affects the achievement of goals related to divisional autonomy and the motivationof divisional managers (e.g., Burns 1980; Tang 1982; Al-Eryani et al., 1990; Johnson and Kirsch 1991; Cravens 1992; Borkowski 1996; Vidal \& Goetschalckx 2001; Smith, 2002b; Baldenius et al., 2004; Chan et al., 2006; Gox \& Schiller, 2007; Villegas \& Ouenniche, 2008; Cools \& Emmanuel, 2007; Cools \& Slagmulder, 2009; Doupnik \& Perera, 2009). However, focusing on subsidiary goals can conflict with the goal of maximizing the short run profit of the parent division.

MNEs also strive to minimize risks associated with their economic, political and operational environment. These risks include; currency fluctuations, inflation and sociopolitical turmoil. These risks can be partially minimized by moving capital out of the foreign countries through actions such as the repatriation of dividends (e.g., Kim \& Miller 1979; Tang 1982, 1992; Lecraw, 1985; Al-Eryani et al., 1990; Borkowski, 1996; Doupnik \& Perera, 2009). Risks may also be mitigated by cooperation with the host country and compliance with a number of cash flow and capital restrictions such as those represented by constraints as noted below. Minimizing risks however may conflict with the short term profit maximization and managerial control objectives.

The extent to which these multiple objectives can be optimized is often constrained. Repatriation of capital, for example, may be constrained by the imposition of dividend restrictions (e.g., Kim \& Miller 1979; Tang, 1982 \& 1992; Borkowski 1996; Villegas \& Ouenniche 2008; Doupnik \& Perera 2009). Public policy may require maintenance of cash flow and subsidiary profit levels (e.g., Burns 1980; Tang 1982 and Borkowski 1996) (Note 5). Further, transfer prices themselves are restricted by tax authorities, which set compliance standards (Note 6). Tax restrictions may specify the methods allowed for determining comparable profit margins of similar organizations or products, as well as the potential use of ex ante or ex post manipulation (e.g., Smith, 2002a) of accounting or capital decisions to endogenously affect transfer prices.

The Organization for Economic Co-operation and Development (OECD, 2001; 2009) developed guidelines for transfer pricing agreements, based on an "arms length" standard, which are followed by much of the global community (Ernst \& Young Survey, 2007). The guidelines state that the transfer price between related parties should be, in principle, equivalent to an arms-length transaction. The application of this principle can be complex and there are several acceptable methods that can be used to achieve it. Two of the acceptable methods widely used in practice and used in this study are; the cost plus method and the resale price method (Note 7). We do not illustrate the comparable uncontrolled price method (CUP) because it is difficult to identify comparable uncontrolled transactions.

Smith (2002a) argues that tax auditors can only identify a range of acceptable transfer prices suggesting that there is room for ex post discretion in the selection of what is comparable for the above methods. Smith (2002a) also argues that a firm can manipulate the transfer price ex ante by investment (resources) choices because these choices affect the determination of comparability. Indeed, it is not always easy to detect deviations from an"arms length" price (Note 8). Thus, there appears to be a wide range in which transfer prices can be set (Note 9). These objectives and constraints along with othersare outlined in Leitch and Barrett (1992) (Note 10). In summary, the setting of an optimal or satisfactory transfer price is a very complex managerial accounting problem.

\section{Multiple Objective Linear Programming and the Search Process}

A multiple objective mathematical programming problem can be characterized as

$$
\max \left\{U\left(z_{1}, \ldots, z_{k}\right)\right\} \text {, s.t. } F_{i}(\mathbf{x})=z_{i}, i \in K, \mathbf{x} \in S
$$

where $K=\{1 \ldots k\}, U$ is the Manager's utility, $F_{i}(\mathbf{x})$ (bold letters denote a vector throughout the manuscript) 
is the objective function $i=1, \ldots, k, z_{i}$ is the objective or criterion value, and $S$ is the feasible region of actions in decision space (or task domain) needed to reach an optimal or satisfactory solution based on $U$. It is often not possible to obtain an accurate enough representation of $U$ due to the complexity of relationships between the objectives in a MOLP, as discussed earlier. Consequently, it is more productive to couch our problem in MOLP form:

$$
\max \left\{F_{1}(\mathbf{x})=z_{1}\right\} \ldots \max \left\{F_{k}(\mathbf{x})=z_{k}\right\}, \text { s.t. } \mathbf{x} \in S
$$

There have been several approaches to solving such a MOLP. An early comparison of these can be found in Leitch et al. (1995, Table 2). As detailed in Leitch et al. (1995), some procedures are very elegant, such as inGeoffrion et al. (1972), but result in long lists of pairwise comparisons of solutions, some of which may be non optimal interior points, and others such as Zionts - Wallenius (1976) and Balachandran and Steuer (1982) may be limited to finding solutions at extreme points. Others, such as the MOLP proposed in Ragsdale (2001) are simply MINMAX extensions of goal programming where the goals are the single objective solution for each objective. To better deal with complex managerial accounting problems such as transfer pricing with (1) ill-defined utility functions (2) large numbers of variables, objectives and constraintswhich may converge to any point (extreme or non-extreme) on the efficient frontier (3) andthe need for decision makers to learn about tradeoffs among objectives in an iterative process, we adapta combination of the Tchebycheffmethod of Steuer and Choo (1983) and the Aspiration Criterion Vector method of Wierzbicki (1980), which Steuer et al. (1993) call the Combined Tchebycheff/Aspiration method (also referred to as the "MOLP search process"or the "search process" throughout the paper). This method uses the weighted $L_{\infty}$ metric of contours to find an optimal or satisfactory solution on the surface of the efficient frontier, rather than limiting the solution space to corner points, as illustrated in Leitch et al., (1995, Figure 3).

Following Steuer (1986; 2001; 2006) and Steuer et al. (1993) in solving a MOLP (Note 11) using the Combined Tchebycheff/Aspiration method, each task vector $\mathbf{x} \in S$ represents the set of tasks or actions needed to achieve $U$ and yields an equivalent criterion vector $\left(F_{1}(\mathbf{x}), \ldots, F_{k}(\mathbf{x})\right)=z \in R^{k}$, where $k$ is the number of objective functionsand each objective is a criterion. In equation (2) the set of all feasible criterion vectors form the feasible region in the criterion space, designated $Z$. This is of interest because in multiple-objective problems criterion space significantly reduces the size of the problem by showing management a range of objective function results so that tradeoffs can be more intelligently assessed. In our illustration in the following sectionwe provide specific examples for $F_{i}(\mathbf{x})$

In a MOLP, $\overline{\mathbf{z}} \in Z$ is a nondominated criterion vector if and only if there does not exist another $\mathbf{z} \in Z$ such that $z_{i} \geq \bar{z}_{i}$ for all $i \in K$ and $z_{i}>z_{i}$ for at least one $i \in K$. The set of all nondominated criterion vectors is called the nondominated set. The nondominated set is important because it determines the feasible region in which management can compare solutions. This allows management to look at the range of objective function values over the nondominated set. If $\mathbf{z}^{h} \in Z$ maximizes the manager's utility function $U$ over $Z$, $\mathbf{z}^{h}$ (where $h$ denotes the iteration number of the search process, this is more fully explained below) is an optimal criterion vector. If we have the usual case in which $U$ is coordinatewise increasing (i.e., more is always better than less of each criterion), $\mathbf{z}^{h}$ is nondominated (Steuer (1986) Theorem 6.11). This means that if we can find the best point in the nondominated set, then we have found an optimal solution. Unfortunately, when the size of the nondominated set is large, finding the best point is not a trivial task, so management must often settle for a satisfactory solution.

Since we cannot calculate $U$ with certainty, we look to the nondominated set to help form our expectations. $\mathbf{z}^{\text {ref }}$ is the reference criterion vector where:

$$
z_{i}^{r e f}=\max _{\mathbf{x} \in S} F_{i}(\mathbf{x})
$$

We form $\mathbf{z}^{\text {ref }}$ to establish an "ideal" criterion vector against which other criterion vectors might be compared. We also form $z_{i}^{\text {nad }}=\min _{\mathbf{x} \in S} F_{i}(\mathbf{x})$, which expresses the minimum values for all objectives. $\mathbf{z}^{\text {ref }}$ together with $\mathbf{z}^{\text {nad }}$ form the limits of the solution space (see Figure 1). 


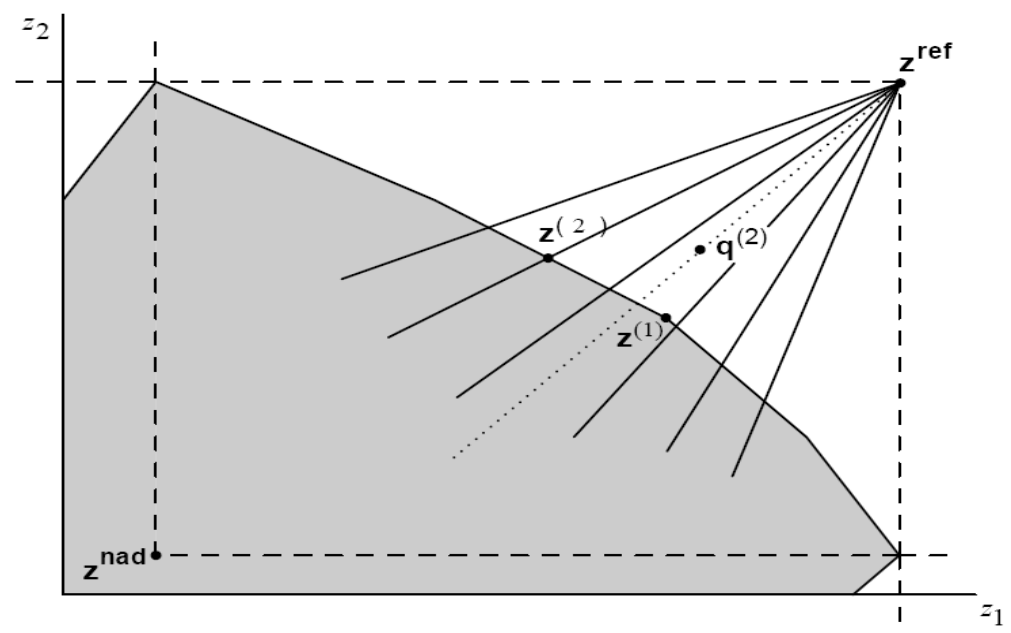

Figure 1. Graphic illustration of combined tchebycheff search process (Steuer et al. 1993)

To initialize the problem we first compute all extreme points (Note 12) and from those we form $\mathbf{z}^{\text {ref }}$ and $\mathbf{z}^{\text {nad }}$. This fixes a point above $Z$ from which downward probes can be made to sample the nondominated set. The downward probes enable management to choose an optimal preferred point from the nondominated set and then probe the area around it to explore other possible solutions (non extreme points on the surface or efficient frontier of the feasible region). This actionwould not be possible with goal programming or with other non-search oriented MOLP methods. The search process enables management to span the entire range of solutions (Perron et al., 2010).

Management chooses the extreme point $\mathbf{z}^{(1)}$, which is the initially preferred extreme point in the nondominated set (management need not understand the mathematical dynamics of the problem, they only need to understand the results and the tradeoffsamongthe objectives). Management then narrows the search to the vicinity (neighborhood) of their favorite solution. This is accomplished by downward probes into the nondominated setrepresented by the rays shown in Figure 1. The rays are formed by weighted vectors that minimize the distance between $\mathbf{z}^{\text {ref }}$ and the nondominated set. This iterative process continues until management reaches a satisfactory set of results. The MOLP search process allows management to choose either a favorite point or an aspiration at each iteration. An aspiration is a point that is defined by management to take the problem in a desired direction. The aspiration vector is usually similar to an actual result except it is skewed away from objectives that are less important and toward objectives that are more important to management as they learn the tradeoffsbetween objectives as relates to their preferences (utility). The aspiration vector, denoted $\mathbf{q}^{2}$, is illustrated in Figure 1.

The engine of the search process is lambda $(\boldsymbol{\lambda})$, which is the MOLP analog to goal programming weights. The lambda vector determines the weights on $\mathbf{z}$ and $\mathbf{q}$ expost, as opposed to goal programming, where the weights are determined a priori. This is a main strength of theMOLP search process as the weights are difficult (impossible) to figure out accurately a priori. It is, however, possible for management to choose the results that suit them best and then view the neighborhood around those results by tweaking $\lambda$.

After theoriginal extreme points are found the MOLP function shifts to the following form:

$$
\min \alpha \text { s.t. } \alpha \geq \lambda_{i}\left(z_{i}^{\text {ref }}-z_{i}\right), \quad F_{i}(\mathbf{x})=z_{i}, \quad \mathbf{x} \in S
$$

This program gives the solution that minimizes the maximum deviation $(\alpha)$ of an objective function result $\left(z_{i}\right)$ from its reference criterion point $\left(z_{i}^{\text {ref }}\right)$. The lambdas $\lambda_{i}$ determine the weights on each objective such that $\sum_{k} \lambda_{i}=1 \cdot \lambda$ is determined by function 2.5 below:

$$
\lambda_{i}=\frac{1}{\left|z_{i}^{r e f}-\left[q_{i}^{(h)} \mid z_{i}^{(h)}\right]\right|}\left[\sum_{j \in K} \frac{1}{\left|z_{j}^{r e f}-\left[q_{i}^{(h)} \mid z_{i}^{(h)}\right]\right|}\right]^{-1}
$$

Where $q_{i}^{(h)}$ (aspiration) or $z_{i}^{(h)}$ (favorite result) can be used interchangeably based on management's 
preference.

The attractiveness of this approach lies in the fact that management can view an arbitrary number of potential solutions in terms of the objectives in the criterion space in the neighborhood of $\mathbf{z}^{h}$ or $\mathbf{q}^{h}$. Each of these solutions (usingEquation (2.4)) depend on a different $\lambda$ vector, i.e., a different set of weights. The manager can produce an arbitrary number of these $\lambda \mathrm{s}$ conforming to:

$$
\lambda=\left\{\lambda_{i} \in R^{k} \mid \lambda_{i} \in(0,1), \sum_{i \in k} \lambda_{\mathrm{i}}=1\right\}
$$

The task at each iteration is to create ${ }_{\text {some }} \lambda_{j}$ close to (biit not necessarily equal to) $\lambda^{(h-1)}$. This is accomplished by setting a range around $\lambda^{(h-1)}$ such that:

$$
\lambda_{j}{ }^{(h)}=\left\{\lambda \in R^{k} \mid \lambda_{i} \in\left(\ell_{i}^{(h)}, \mu_{i}^{(h)}\right), \sum_{\mathrm{i} \in \mathrm{k}} \lambda_{\mathrm{i}}=1\right\}
$$

Where $j$ represents the index of the candidate $\lambda$. The user defines the size of the neighborhood by choosing an interval of size $b=\mu_{i}^{(h)}-\ell_{i}^{(h)}$ with $\lambda^{(h-1)}$ at its center. The tightening of the intervals helps management steer the search process toward a satisfactory solution as theyiterate. The closer $\mathbf{z}^{(h-1)}$ is to management's desired solution based on an often ill-defined $U$, the smaller the interval $b$ will be. In essence, management starts the search process by spanning a large portion of the feasible nondominated solutions to assess the tradeoffs among the solution sets at each iteration, then narrows the range of the search in each successive iteration. Thus, the iterative nature of the process shrinks $b$, narrowing the range of desirable solutions to those more closely aligned with management's ill-defined $U$. It is important that $\lambda_{j, j=1 \ldots k}$ be well-spaced so that management gets a good view of the possibilities in the neighborhood of the more desirable solutions (and does not get duplicate results). This spacing is achieved by initially gathering a large number of $\lambda_{j}$ vectors (using Adbase (Steuer 2006)) then filtering through those vectors to achieve the number of $\boldsymbol{\lambda}_{j}$ vectors (solutions) that management wants (denoted $k$ ).

The steps to the Combined Tchebycheff procedure are summarized below:

(i) Solve the MOLP and retrieve all nondominated solutions. In this step $\mathbf{z}^{\text {nad }}$ and $\mathbf{z}^{\text {ref }}$ are computed from the nondominated solutions, giving the solution space (see Figure 1).

(ii) Management chooses the solution $\mathbf{z}^{(1)}$ from the nondominatedset that most closely aligns with their preference for objectives (see Figure 1).

(iii) Equation (2.5) is used to calculate $\lambda^{(h)}$ for $\mathbf{z}^{(h)}$ or $\mathbf{q}^{(h)}$ ( $h$ represents the iteration number, for the first iteration $h=1$.

(iv) $\quad \lambda^{(h)}$ and a user-defined interval $b=\mu_{i}^{(h)}-\ell_{i}^{(h)}$ are used to create $k$ well-spaced $\lambda_{j, j=1 \ldots k}$ in the neighborhood of $\lambda^{(h)}$ (using Equation (2.7) as a guide). Management decides $k$.

(v) The weighted Tchebycheff Sampling Program (2.4) is run for each $\boldsymbol{\lambda}_{j}$.

(vi) Management chooses their preferred result $\mathbf{z}^{(h)}$.

(vii) Management decides if they are satisfied with the result or if they want to iterate through again, tightening their search criteria. If they choose to iterate again they decide if they want to use $\mathbf{z}^{(h)}$ (preferred solution) or $\mathbf{q}^{(h)}$ (aspiration). The process continues at Step 3 and $h$ becomes $h+1$.

In summary, the Combined Tchebycheff/Aspiration method enables management to refine their preferences through an iterative search process for an otherwise ill-defined utility function as they work with the feasible solutions. Using the search process, learning is facilitated, management identifies the trade-offs to be made, and final solutions at nonextreme points can be found.

\section{Transfer Pricing Illustration and Solutions}

\subsection{Illustrative Model with Constraints}

We assume three divisions (div. 1, 2, and 3) that sell to each other in order (1 sells to 2, 2 sells to 3 and 3 sells to the outside market). Themultinational organization needs to select transfer price $p_{i j}$, where $i$ is the selling division and $j$ is the buying division. There may be many interrelated objectives that the company would like to optimize by choosing appropriate transfer prices. Further, there may be many interrelated constraints. Since MNE transfer prices are often founded on costs, we define total cost, consisting of fixed, variable and transferred-in costs for division $i$, the selling division, as: 


$$
w_{i}=f_{i}+v_{i}+\sum_{k} p_{k i}
$$

where all costs are simply defined as aggregate costs because the same number of units are transferred from one division to the next division in our example. In particular, $w_{i}$ is the total cost, $f_{i}$ is the total fixed cost, $v_{i}$ is the total variable cost, and the transfer price $p_{k i}$ is the total cost of the units transferred into division $i$. Even though transfer prices can be affected by endogenous production activity, we assume units produced and transferred are exogenous. Our object in this example is not to try to find the optimal balance between flow and transfer prices, but to focus on multiple objectives related to the transfer price decision, when the flows of goods are relatively stable or determined through previous decisions.

The key variables used in the model are presented here, in Figure 2, and summarized in Table 1. The cost functions yield the following expressions:

$$
\begin{gathered}
w_{1}=f_{1}+v_{1}=5000+5000 \\
w_{2}=f_{2}+v_{2}+p_{12}=2000+4000+p_{12} \\
w_{3}=f_{3}+v_{3}+p_{23}=500+500+p_{23}
\end{gathered}
$$

where $v_{i}$ (the total variable cost) equals 50, 40, and 5 per unit (we assume 100 units are transferred respectively from divisions 1 to 2,2 to 3 , and 3 to the external market). For simplicity of exposition, we assume all fixed costs are in the form of depreciation and are not cash flows. These equations are shown in Figure 2 where constants are right hand side constraints and all variables are shifted to the left hand side of the equation.

Table 1. Illustration-cost, units transferred, tax rate, comparable markups for transfer prices, and dividend repatriation restriction-endogenous variables

\begin{tabular}{cccccc}
\hline Transfer Pricing Constants & Division 1 & Division 2 & Division 3 & Totals & External Market \\
\hline Units transferred & 100 units & 100 units & 100 units & 100 units & 100 units \\
Final external market price & & & & $\$ 300$ \\
Variable cost per unit & $\$ 50$ & $\$ 40$ & $\$ 5$ & $\$ 95$ & \\
$\quad$ Fixed Costs & $\$ 5,000$ & $\$ 2,000$ & $\$ 500$ & $\$ 10$ & $\$ 170$ \\
Total costs added per unit & $\$ 100$ & $\$ 60$ & $35 \%$ & & \\
Division country tax rates & $5 \%$ & $20 \%$ & & \\
Dividend repatriation restriction & $50 \%$ & & & \\
Transfer price comparable markups & & & & \\
Minimum Cost Plus from division 1 to 2 & $10 \%$ & & & \\
Maximum Cost Plus from division 1 to 2 & $30 \%$ & & & \\
Minimum resale from division 2 to 3 & & & & \\
Maximum resale from division 2 to 3 & & &
\end{tabular}




\begin{tabular}{|c|c|c|c|c|c|c|c|c|c|c|c|c|c|c|c|c|c|c|c|c|c|c|c|c|c|c|c|}
\hline \multirow{4}{*}{$\begin{array}{l}\text { Minimize Deviations } \\
\\
\text { Variable Names }\end{array}$} & \multicolumn{3}{|c|}{4400} & & \multicolumn{2}{|c|}{ Total Profit = } & \multicolumn{2}{|c|}{$9,800 \mathrm{Pl}=$} & \multirow[t]{3}{*}{$2,850 \mathrm{P}$} & \multirow[t]{2}{*}{$\mathrm{P} 2=$} & \multirow{3}{*}{\multicolumn{2}{|c|}{$\begin{array}{l}4,000 \mathrm{P} 3= \\
\text { Cash Flows }\end{array}$}} & \multirow{3}{*}{\multicolumn{3}{|c|}{\begin{tabular}{|ll}
2,950 & \\
& \\
& Taxes \\
\end{tabular}}} & \multicolumn{3}{|c|}{ Repatriated Diidend= } & \multicolumn{2}{|l|}{1,000} & & & & & & \multirow{3}{*}{\multicolumn{2}{|c|}{ Constraints }} \\
\hline & & & & & & & & & & & & & & & & \multicolumn{11}{|c|}{ Deviations } & \\
\hline & \multicolumn{3}{|c|}{ Transfer Prices } & \multicolumn{3}{|c|}{ Siles } & \multicolumn{2}{|c|}{ Total Costs } & & & & & & & & Dividends & & ofit 1 & Profi & fit 2 & Profi & fit 3 & Total P & Profit & Repatriation & & \\
\hline & P12 & P23 & P34 & S12 & $\$ 23$ & $\$ 34$ & Wl & W2 & W3 & $\mathrm{Cl}$ & C2 & C3 & $\mathrm{Tl}$ & T2 & $\mathrm{T} 3$ & DI-3 & al- & al + & a2- & $\mathrm{a} 2+$ & a3- & a3+ & at- & a4+ & a5- a5t & & \\
\hline Valutes & 13,000 & 24,000 & - & 13,000 & 24,000 & 30,000 & 10,000 & 19,000 & 25,000 & 6,850 & 6,000 & 3,450 & 150 & 1,000 & 2,050 & 1,000 & 1,150 & - & - & - & 1,050 & - & 2,200 & - & 0 & 0 & \\
\hline Total Profit & & & & 1 & 1 & 1 & -1 & -1 & -1 & & & & -1 & -1 & -1 & & & & & & & & & -1 & & $=$ & 12,000 \\
\hline Profit A & & & & 1 & . & & -1 & & & & & & -1 & 1 & & & & -1 & & & & & & & & $=$ & 4,000 \\
\hline Profit B & & & & & 1 & & & -1 & & & & & & -1 & & & & & 1 & $\begin{array}{ll}1 & -1\end{array}$ & & & & & & $=$ & 4,000 \\
\hline Profit C & & & & & & 1 & & & -1 & & & & & & -1 & & & & & & 1 & -1 & & & & $=$ & 4,000 \\
\hline Dividend 1-3 & & & & & & & & & & & & & & & & 1 & & & & & & & & & 1 & $1=$ & 1,000 \\
\hline Final Sales Value & & & & & & 1 & & & & & & & & & & & & & & & & & & & & $=$ & 30,000 \\
\hline Cosss Total & & & & & & & & & & & & & & & & & & & & & & & & & & 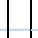 & \\
\hline $\mathrm{Cl}$ & & & & & & & 1 & & & & & & & & & & & & & & & & & & & $=$ & 10,000 \\
\hline C2 & -1 & & & & & & & 1 & & & & & & & & & & & & & & & & & & $=$ & 6,000 \\
\hline C3 & & -1 & & & & & & & 1 & & & & & & & & & & & & & & & & & $=$ & 1,000 \\
\hline Tax Total & & & & & & & & & & & & & & & & & & & & & & & & & & . & \\
\hline $\mathrm{Tl}$ & & & & -0.05 & & & 0.05 & & & & & & 1 & 1 & & & & & & & & & & & & $=$ & - \\
\hline T2 & & & & & -0.2 & & & 0.2 & & & & & & 1 & 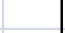 & & & & & & & & & & & $=$ & - \\
\hline $\mathrm{T} 3$ & & & & & & -0.35 & & & 0.35 & & & & & & 1 & -0.3 & & & & & & & & & & $=$ & - \\
\hline Revenue & & & & & & & & & & & & & & & & & & & & & & & & & & 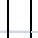 & \\
\hline $\mathrm{Sl}$ & -1 & & & 1 & 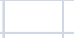 & & & & & & & & & & & & & & & & & & & & & $=$ & - \\
\hline$S 2$ & & -1 & & & 1 & & & & & & & & & & & & & & & & & & & & & $=$ & - \\
\hline S3 & & & & & & 1 & & & & & & & & & & & & & & & & & & & & $=$ & 30,000 \\
\hline Cash Flows & & & & & & & & & & & & & & & & & & & & & & & & & & 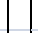 & \\
\hline $\mathrm{Cl}$ & & & & -1 & & & 1 & & & 1 & & & 1 & 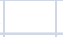 & & 1 & & & & & & & & & & $=$ & 5,000 \\
\hline $\mathrm{C} 2$ & & & & & -1 & & & 1 & & & 1 & & & 1 & 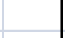 & & & & & & & & & & & $=$ & 2,000 \\
\hline C 3 & & & & & & -1 & & & 1 & & & 1 & & & 1 & 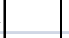 & & & & & & & & & & $=$ & 500 \\
\hline Minimum TP & & & & & & & & & & & & & & & & & & & & & & & & & & 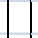 & \\
\hline P12 & 1 & & & & & & & & & & & & & & & & & & & & & & & & & $>$ & 5,000 \\
\hline $\mathrm{P} 23$ & -1 & 1 & & & & & & & & & & & & & & & & & & & & & & & & 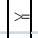 & 4,000 \\
\hline Minimum TP Markup & & & & & & & & & & & & & & & & & & & & & & & & & & & \\
\hline 1-2 Cost Plus & 1 & & & & & & -1.1 & & & & & & & & & & & & & & & & & & & $>$ & - \\
\hline 2-3 Resale & & 1 & & & & & & & & & & & & & & & & & & & & & & & & $\Rightarrow$ & 23,077 \\
\hline Maximum TP Markup & & & & & & & & & & & & & & & & & & & & & & & & & & & \\
\hline 1-2 Cost Plus & 1 & & & & & & -1.3 & & & & & & & & & & & & & & & & & & & $<=$ & - \\
\hline 2-3Resale & & 1 & & & & & & & & & & & & & & & & & & & & & & & & $<$ & 27,273 \\
\hline Dividend Repatration & & & & -0.5 & & & 0.5 & & & & & & 0.5 & & & 1 & & & & & & & & & & $<$ & - \\
\hline
\end{tabular}

Figure 2. Goal programming solution for minimizing deviations from total profit, dividend repatriation targets

Total internal sales $s_{i j}$ are between division $i$ and $j$ at the transfer price $p_{i j}$ and ultimately to the outside market at a market price $\mathrm{m}$. Thus from divisions 1 to 2 and 2 to 3 we have $s_{i j}=p_{i j}$ and external sales to the outside market (noted in Figure 2 as $j=4$ ) for division 3 are $s_{34}=m$. Thus, total divisional sales shown in Figure2 are equivalent to the transfer price for our illustration as follows:

$$
\begin{aligned}
s_{12} & =p_{12} \\
s_{23} & =p_{23} \\
s_{34}=m & =30,000
\end{aligned}
$$

Total taxes $t_{i}$ for division $i$ are a function of sales $s_{i j}$, total costs for each division $w_{i}$, the tax rate for each division $r_{i}$ and if applicable, a function forthe recapture of taxes paid by foreign subsidiaries to their host counties forany dividends $d_{k}$ repatriated from foreign subsidiary $k$. Thus

$$
t_{i}=r_{i} s_{i}-r_{i} w_{i}+r_{i} \sum_{k=1}^{n} d_{k}-\sum_{k=1}^{n} r_{k} d_{k}
$$

For $i \neq k$ and $n$ is the number of divisions that dividends can be repatriated from. Taxes are paid on the sales less the costs plus any dividends repatriated from foreign subsidiary $k$. A tax credit is given for those taxes paid in the host country wherethe foreign division $k$ resides for those dividends repatriated. Thus, the total taxes for each division, assuming only the home division 3 receives repatriated dividends from foreign 
subsidiary 1,are shown in Figure2and are as follows:

$$
\begin{gathered}
t_{1}=r_{1} s_{1}-r_{1} w_{1} \\
t_{2}=r_{2} s_{2}-r_{2} w_{2} \\
t_{3}=r_{3} s_{3}-r_{3} w_{3}+r_{3} d_{13}-r_{1} d_{13}
\end{gathered}
$$

Total cash flow $c_{i}$ for division $i$ is equal to sales $s_{i j}$ less variable costs $\left(v_{i}=w_{i}-f_{i}\right)$ less the taxes $t_{i}$ for each division, not including dividend repatriation. Thus:

$$
c_{i}=s_{i}-\left(w_{i}-f_{i}\right)-t_{i}
$$

In particular, including dividend repatriation $d_{13}$ for each of the divisions the cash flows may be expressed as

$$
\begin{aligned}
c_{1}= & s_{1}-\left(w_{1}-f_{1}\right)-t_{1}-d_{13}=s_{1}-\left(w_{1}-5000\right)-t_{1}-d_{13} \\
& c_{2}=s_{2}-\left(w_{2}-f_{2}\right)-t_{2}=s_{2}-\left(w_{2}-2000\right)-t_{2} \\
c_{3}= & s_{3}-\left(w_{3}-f_{3}\right)-t_{3}+d_{13}=s_{3}-\left(w_{3}-500\right)-t_{3}+d_{13}
\end{aligned}
$$

where the cash flow for each division is defined by virtue of the model shown in Figure 2 as a positive value for each division.

The minimum transfer price $p_{12}$ must be greater than the variable costs $v_{i}$, which include transferred in costs $p_{k i}$ from the previous division $k$. Thus:

$$
p_{i j} \geq v_{i}+p_{k i}
$$

For each of the divisions this constraint may be expressed as:

$$
\begin{gathered}
p_{12} \geq v_{1}=5000 \\
p_{23} \geq v_{2}+p_{12}=4000+p_{12}
\end{gathered}
$$

From the earlier discussion on transfer prices it is clear that there are there are upper and lower limits on what maybe considered a comparable markup, whether based on the total cost using the cost plus method or based on the selling price using the resale method. We illustrate both in that we assume that $P_{12}$ is based on the cost plus method and $P_{23}$ is based on the resale method. Assuming that the maximum markup $m u$ is $30 \%$ and the minimum markup $\mathrm{ml}$ is $10 \%$ of cost in both cases, we have an upper bound and lower bound on the transfer price respectively:

$$
\begin{aligned}
& p_{12} \geq(1+m l) w_{1}=1.1 w_{1} \\
& p_{12} \leq(1+m u) w_{1}=1.3 w_{1}
\end{aligned}
$$

For $p_{23}$, which is based on the ultimate selling price $m$ :

$$
\begin{aligned}
& p_{23} \leq m /(1+m l)=30000 / 1.1 \\
& p_{23} \geq m /(1+m l)=30000 / 1.3
\end{aligned}
$$

where $30,000=300 * 100$ units sold to the outside market by division 3 at the end of the process.

We next define profit $\Pi_{i}$ for each division $i$ as sales $s_{i}$ minus total costs $w_{i}$ minus total taxes $t_{i}$. Initially, in solving the single objective problem of maximizing total profit we set these to be greater than or equal to zero. In particular, the profit for each of the divisions may be expressed as:

$$
\Pi_{i}=s_{i}-w_{i}-t_{i}
$$

We also have an additional constraint imposed by division one's host country that no more than 50 percent of the profits may be repatriated as dividends by the parent company. Thus, repatriated dividends from division 1 to 3 are constrained as follows:

\subsection{Illustrative Objectives}

$$
d_{13} \leq 0.5 \prod_{1}
$$

We solve the illustrative problem three ways. We first simply maximize total profit, whichis typical of many 
international transfer-pricing illustrations. We next use goal programming (Note 13) to find the minimum deviation from a set of goals that represent multiple objectives. Finally, we use the Combined Tchebycheff/Aspiration MOLP method to solve the problem and illustrate the advantage of this method.

As is common in single objective models the objective is to maximize total profit $\Pi$, which is tantamount to minimizing total taxes:

where profit is defined for each division $i$ as:

$$
\underset{\text { Max }}{ } \Pi=\sum_{i}^{n} \Pi_{i}=\Pi_{1}+\Pi_{2}+\Pi_{3}
$$

$$
\Pi_{i}=s_{i}-w_{i}-t_{i}
$$

constrained to be greater than or equal to zero as shown in Figure 1

$$
\begin{gathered}
\Pi_{1}-s_{1}+w_{1}+t_{1} \geq 0 \\
\Pi_{2}-s_{2}+w_{2}+t_{2} \geq 0 \\
\Pi_{3}-s_{3}+w_{3}+t_{3} \geq 0
\end{gathered}
$$

\subsection{Single Objective and Goal Programming Solutions}

When we only maximize the total profit we do not utilize any of the deviation variables for dividend repatriation or deviations from an equal distribution of profit (which are shown in Figure 2 but are not operational). These deviation variables are described below as part of a goal programming solution and for purposes of the single objective are simply calculated from the results as summarized in table 2 .

Table 2. Results summary for the total profit model, the goal programming models, and the MOLP search process

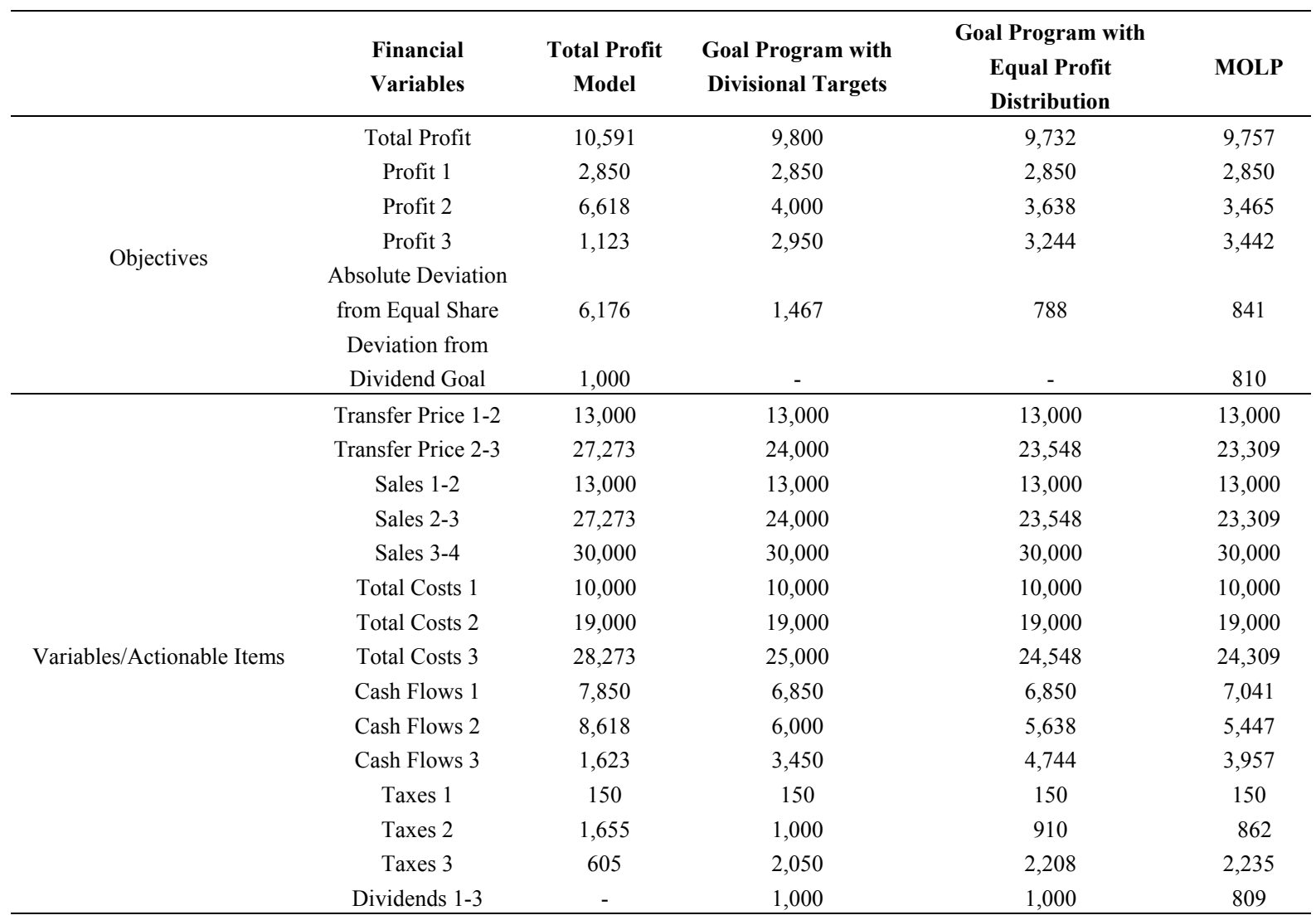

We next consider multiple objectives using goal programming. We again seek to maximize the total profit, which is the overall goal, by minimizing the deviation from a target profit. Along with this goal we seek to minimize the deviation from a target profit for each division by setting this target to be equal to one-third of the total overall target profit, in the spirit of an equitable distribution of profit. We also set a target for the dividends 
we want to repatriate from division 1 . This target aims to repatriate a portion of the cash at risk based on the assumption that Division 1's home country carries some socio-political or economic risk.

Using goal programming we set goals for the objectives and minimize deviations from these objectives. These goals can be weighted as to their importance and their relative size (e.g., Ragsdale 2001). Our units are all in dollars so size is not an issue. We choose not to weight our program due to the arbitrary nature of the weights (althoughweights couldeasily be added). Deviations $a^{+}$and $a^{-}$are used to express the amount over the goal and under the goal, respectively. As a result we revise the profit expressions above to be (the individual divisional goals are also shown in figure 2):

$$
\begin{gathered}
\Pi_{1}-s_{1}+w_{1}+t_{1}+a_{1}^{-}-a_{1}^{+}=4000 \\
\Pi_{2}-s_{2}+w_{2}+t_{2}+a_{2}^{-}-a_{2}^{+}=4000 \\
\Pi_{3}-s_{3}+w_{3}+t_{3}+a_{3}^{-}-a_{3}^{+}=4000
\end{gathered}
$$

We then express an overall goal for total profit using deviation variables:

$$
\sum_{i}^{n} \Pi_{i}+a_{4}^{-}-a_{4}^{+}=\Pi_{1}+\Pi_{2}+\Pi_{2}+a_{4}^{-}-a_{4}^{+}=12000
$$

where 12,000 is in excess of the unconstrained maximum profit and the individual profit goals are each one third of this total goal.

We then express deviations from a goal of moving $\$ 1,000$ of dividends out of division 1 for socio-political or economic reasons related to risk.

$$
d_{13}+a_{5}^{-}-a_{5}^{+}=1000
$$

The results of the goal program solution are presented in Table2. As can be seen there is morebalance between the profit of each division compared to the single objective of maximizing total profit alone, some cash is moved from division 1 and overall profit is $\$ 9,800$ (instead of $\$ 10,591$ when only the total profit is maximized). As we expect there is a reasonable balance among all these objectives, subject to the constraints, given that the objectives were not weighted. The objectives could be weighted absolutely or relatively (e.g., Ragsdale 2001); but setting such weights a priori is very difficult because the goals conflict and are correlated and tradeoffs among objectives are difficult to assess.

In an alternative version of the goal program presented in Figure 2 we can express deviations from $\Pi / 3$ as equal distribution of profit objective, rather than deviations from the predetermined divisional profit level of $\$ 4,000$. These deviations are:

$$
\Pi / 3-\Pi_{i}+a_{i}^{-}-a_{i}^{+}=0
$$

where $i$ is denoted as 6 through 8 representing divisional profit deviations from the average profit (one third the total) for divisions 1 through 3 respectively. This formulation results in an even more equitable distribution of divisional profit. The results are presented in Table 1 . The total profit is now $\$ 9,732$.

The problem with goal programming is that management must first determine appropriate goals and then determine a set of absolute or relative weights. As noted in Leitch et al. (1995), Einhorn and Hogarth (1981), and Balachandran and Steuer (1982)it is a difficult challenge to determine an appropriate set of weights for complex problems (such as the transfer pricing problem). Indeed, as noted by Morse (1978) and Zeleny (1983),model specifications such as weights may be better derived interactively because they are dependent on the set of feasible alternatives and cannot be knowna priori as required with goal programming (Note 14). Next we illustrate the Combined Tchebycheff/Aspiration MOLP method as a way to circumvent the need to generate weights a priori, instead allowing management to figure out weights interactively.

\subsection{Combined Tchebycheff/Aspiration MOLP Solution}

Using the MNE transfer pricing problem as an example we illustrate the search process using the Combined Tchebycheff/Aspiration MOLP method. Instead of simply minimizing the sum of deviations (which can be weighted) from targets, we consider multiple objectives explicitly. Figure 3 summarizes the objectives and constraints in the MOLP. The differences between the MOLP formulation and the GP are minimal. The MOLP formulation deals with deviations a bit differently than the GP. In the MOLP formulation there is an extra variable that is constrained to equal $1 / 3$ of total profit. The difference in this variable and the profit for a division is the deviation for that division. 


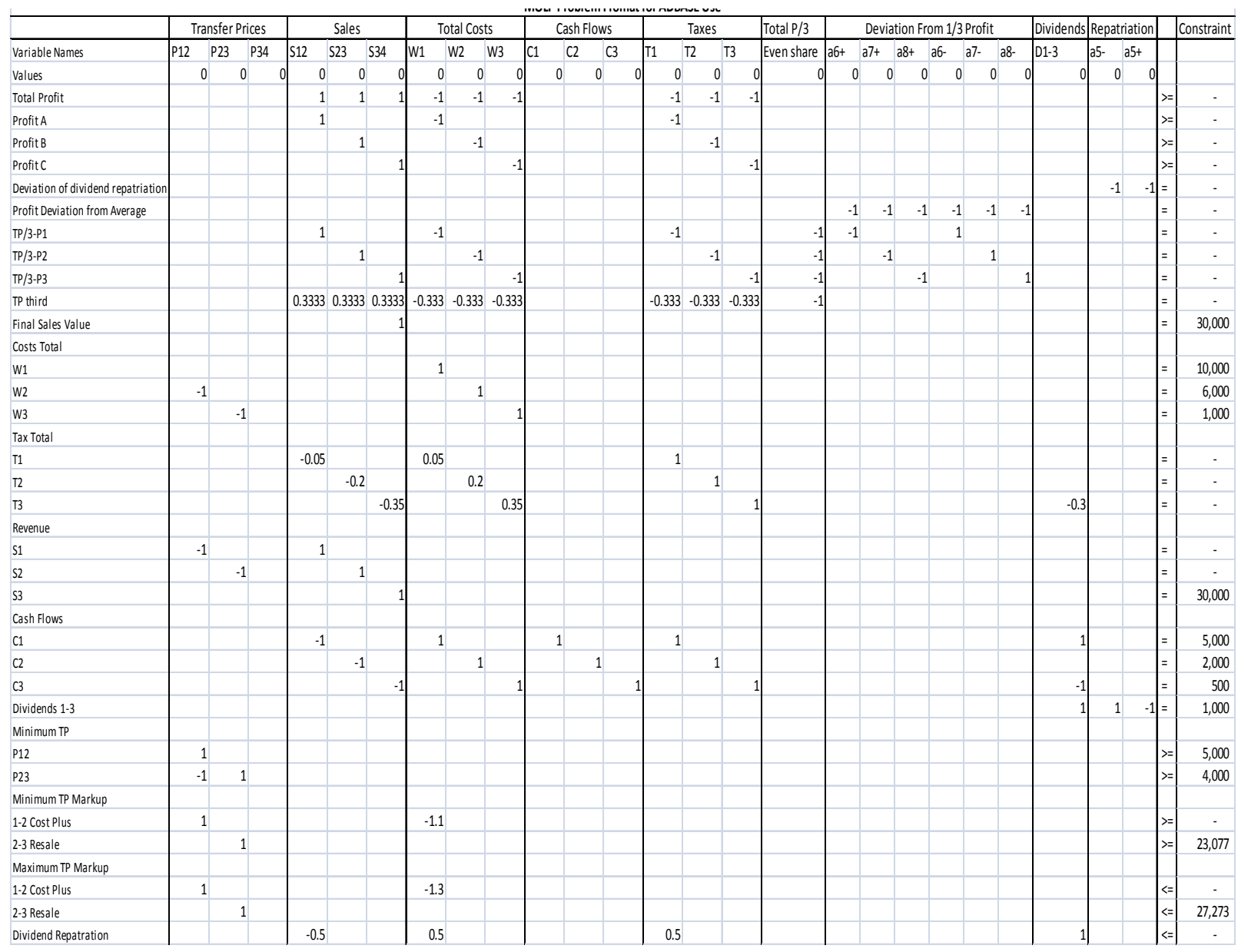

Figure 3. MOLP problem format from adbase use

The process starts with maximizing all objectives simultaneously using Adbase (Steuer \& Choo, 1983). There are a number of feasible results in the initial run since there are many combinations of optimal (nondomindated) solutions. The full set of results is shown in Table 3 and consists of twenty candidate solutions. From viewing this set one can see that there are a wide variety of results for management to choose from. This is what is expected of the first pass (Step 1 of the search process). 
Table 3. First iteration MOLP results

\begin{tabular}{ccccccc}
\hline \multirow{2}{*}{ Result \# } & $\begin{array}{c}\text { Total } \\
\text { Profit }\end{array}$ & $\begin{array}{c}\text { Division 1 } \\
\text { Profit }\end{array}$ & $\begin{array}{c}\text { Division } 2 \\
\text { Profit }\end{array}$ & $\begin{array}{c}\text { Division } 3 \\
\text { Profit }\end{array}$ & $\begin{array}{c}\text { Deviation from Equal } \\
\text { Profit }\end{array}$ & $\begin{array}{c}\text { Deviation from Dividend } \\
\text { Goal }\end{array}$ \\
\hline 1 & $9,519.05$ & 950.00 & $4,861.60$ & 3707.45 & $-4,446.35$ & -525.00 \\
2 & $9,527.34$ & $2,000.00$ & $3,977.39$ & 3549.95 & $-2,351.88$ & 0.00 \\
3 & $9,534.05$ & $2,850.00$ & $3,261.60$ & 3422.45 & -656.35 & -425.00 \\
4 & $9,586.50$ & $2,850.00$ & $3,541.32$ & 3195.18 & -691.32 & -425.00 \\
5 & $9,607.59$ & $2,000.00$ & $4,405.38$ & 3202.21 & $-2,405.38$ & 0.00 \\
6 & $9,633.64$ & 950.00 & $5,472.75$ & 3210.89 & $-4,522.75$ & -525.00 \\
7 & $9,661.55$ & $2,850.00$ & $3,261.60$ & 3549.95 & -741.36 & 0.00 \\
8 & $9,661.55$ & 950.00 & $4,861.60$ & 3849.95 & $-4,541.36$ & $-1,000.00$ \\
9 & $9,732.21$ & $2,850.00$ & $3,638.47$ & 3243.75 & -788.47 & 0.00 \\
10 & $9,785.78$ & $2,850.00$ & $3,261.60$ & 3674.18 & -824.18 & -414.10 \\
11 & $9,796.50$ & 950.00 & $5,581.33$ & 3265.17 & $-4,631.33$ & $-1,000.00$ \\
12 & $9,951.21$ & $2,784.52$ & $3,316.74$ & 3849.95 & $-1,065.43$ & $-1,000.00$ \\
13 & $9,961.55$ & $2,850.00$ & $3,261.60$ & 3849.95 & $-1,058.54$ & $-1,000.00$ \\
14 & $9,973.27$ & $2,850.00$ & $3,324.09$ & 3799.18 & -949.18 & $-1,000.00$ \\
15 & $10,075.07$ & $2,850.00$ & $3,867.05$ & 3358.02 & $-1,017.05$ & $-1,000.00$ \\
16 & $10,148.45$ & 950.00 & $8,218.40$ & 980.05 & $-9,670.83$ & -525.00 \\
17 & $10,156.74$ & $2,000.00$ & $7,334.19$ & 822.55 & $-7,896.88$ & 0.00 \\
18 & $10,290.95$ & $2,850.00$ & $6,618.40$ & 822.55 & $-6,375.82$ & 0.00 \\
19 & $10,290.95$ & 950.00 & $8,218.40$ & 1122.55 & $-9,575.82$ & $-1,000.00$ \\
20 & $10,590.95$ & $2,850.00$ & $6,618.40$ & 1122.55 & $-6,175.81$ & $-1,000.00$ \\
\hline
\end{tabular}

Management would peruse these solutions and choose one that most closely matches their utility. For example, suppose management is interested in balancing profit objectives (low deviation from equal profit) along with maintaining a fairly high total profit and a fairly low deviation from their dividend repatriation goal. In this case they might choose Solution 10, making it $\mathbf{z}^{(1)}$ (step 2 of the search process). $\boldsymbol{\lambda}^{(1)}$ (ex-post weights) are calculated using function 2.5(Step 3) which takes as input the single objective optimal solution vector ( $\mathbf{z}^{\text {ref }}$ ) together with Solution 10. Function 2.5 calculates the implicit weight placed on each objective. These weights would be very difficult (if not impossible) to obtain a priori due to the complexity of the problem and the difficulty inherent in understanding the confounding affects of the interactions and conflicts among the objectives.

Since management is interested in probing for further nondominated solutions but would like to stay in the general neighborhood of their choice, a range $b$ is given to determine how wide a net to cast. In this example we start with $b=0.05$. Adbase then performs a two step process. First it generates a large number of lambdas and then it filters them down to an evenly spaced smaller set of between six and eight $\lambda_{i}$ (Step 4). Each $\lambda_{i}$ in this final set is inserted into function 2.4and a new set of results is obtained (Step 5) (Note 15). These results are reported in Table 4. Comparing the results in Table 4 to Solution 10 in Table 3 it is easy to see that these solutions are in the same neighborhood. 
Table 4. 2nd iteration MOLP results

\begin{tabular}{ccccccc}
\hline Result \# & Total Profit & Division 1 Profit & Division 2 Proift & Division 3 Profit & Deviation from Equal Profit & $\begin{array}{c}\text { Deviation from } \\
\text { Dividend Goal }\end{array}$ \\
\hline 1 & $9,546.28$ & $2,850.00$ & $3,261.54$ & $3,434.74$ & -664.19 & -384.20 \\
2 & $9,588.42$ & $2,769.70$ & $3,622.58$ & $3,196.14$ & -852.88 & -384.85 \\
3 & $9,984.32$ & $2,850.00$ & $3,383.03$ & $3,751.29$ & $-2,267.37$ & $-1,000.00$ \\
4 & $9,984.32$ & $2,850.00$ & $3,383.03$ & $3,751.29$ & $-2,267.37$ & $-1,000.00$ \\
5 & $10,044.75$ & $2,850.00$ & $5,190.42$ & $2,004.33$ & $-3,684.33$ & -71.81 \\
6 & $10,162.12$ & $2,812.50$ & $4,394.46$ & $2,955.16$ & $-2,641.81$ & $-1,000.00$ \\
7 & $10,284.12$ & $2,850.00$ & $4,981.95$ & $2,452.16$ & $-3,695.93$ & $-1,000.00$ \\
8 & $10,580.39$ & $2,783.36$ & $6,674.30$ & $1,122.73$ & $-6,569.36$ & $-1,000.00$ \\
\hline
\end{tabular}

Suppose Management favors Solution 1 (Step 6), we would make $_{\mathbf{z}}{ }^{(2)}$ equal to Solution 1. The next decision is whether to continue or use $\mathbf{z}^{(2)}$ as our final solution or iterate again. Suppose we choose to continue (Step 7). We decide this time to create an aspiration vector $\mathbf{q}^{(2)}$ (based closelyon $\mathbf{z}^{(2)}$ ), where $\mathbf{q}^{(2)}=(9,550,2850$, $3275,3450,-650,-400)$. $\lambda^{(2)}$ for $\mathbf{q}^{(2)}$ is then found using Adbase. Using $b=0.05$ again a large number of random $\lambda_{i}$ are created and then filtered to between six and eight solutions and a new set of results is calculated and reported in Table 5.

Table 5. 3rd iteration MOLP results

\begin{tabular}{ccccccc}
\hline Result \# & Total Profit & $\begin{array}{c}\text { Division } 1 \\
\text { Profit }\end{array}$ & $\begin{array}{c}\text { Division 2 } \\
\text { Proift }\end{array}$ & $\begin{array}{c}\text { Division 3 } \\
\text { Profit }\end{array}$ & $\begin{array}{c}\text { Deviation from Equal } \\
\text { Profit }\end{array}$ & $\begin{array}{c}\text { Deviation from } \\
\text { Dividend Goal }\end{array}$ \\
\hline 1 & $9,773.17$ & $2,850.00$ & $3,463.79$ & $3,459.38$ & -829.73 & -245.71 \\
2 & $9,918.29$ & $2,850.00$ & $3,261.54$ & $3,806.75$ & $-1,088.77)$ & -855.84 \\
3 & $10,009.37$ & $2,591.64$ & $4,179.54$ & $3,238.19$ & $-1,686.17$ & -857.65 \\
4 & $10,067.58$ & $2,633.13$ & $4,386.54$ & $3,047.91$ & $-2,061.36$ & -878.64 \\
5 & $10,104.80$ & $2,652.81$ & $4,526.35$ & $2,925.64$ & $-2,333.69$ & -894.60 \\
6 & $10,113.10$ & $2,665.57$ & $4,548.45$ & $2,899.08$ & $-2,354.84$ & -895.04 \\
7 & $10,312.97$ & $2,850.00$ & $5,135.85$ & $2,327.12$ & $-3,396.39$ & $-1,000.00$ \\
\hline
\end{tabular}

Suppose the result with the lowest deviations from an equitable distribution of profit, result number $1\left(\mathbf{z}^{(3)}\right)$, is the one management prefers in our illustration. Since the goal is to narrow in on an acceptable set of optimal results management chooses to continue with another iteration, but this time tightens the search range to $b=0.02 \cdot \lambda^{(3)}$ is calculated and a range of 0.02 around $\lambda^{(3)}$ is used for the final iteration. The random $\lambda_{i}$ are created and filtered and our MOLP method is run again and reported in Table 6. At this stage the variation in objective function values is less than before, due to the tighter range. Assume that it is now likely one of the seven reported results would be acceptable and the search process would stop (were management not satisfied the iteration process could continue by narrowing $b$ or trying a new aspiration vector if the range of results is deemed not satisfactory by management). Table 6 also reports $\lambda$ for the final results. From viewing $\lambda$ the reader can see that each row adds up to 1 . It is also apparent that one would have a hard time guessing this set of weights a priori as is required in goal programming. Viewing the columns shows that the variation in weights among the final set of results is no greater than 0.04 (which is a range of $2 b$ ). 
Table 6. 4th iteration MOLP results and lambda weights

\begin{tabular}{ccccccc}
\hline Result \# & Total Profit & $\begin{array}{c}\text { Division 1 } \\
\text { Profit }\end{array}$ & $\begin{array}{c}\text { Division 2 } \\
\text { Proift }\end{array}$ & $\begin{array}{c}\text { Division 3 } \\
\text { Profit }\end{array}$ & $\begin{array}{c}\text { Deviation from } \\
\text { Equal Profit }\end{array}$ & $\begin{array}{c}\text { Deviation from } \\
\text { Dividend Goal }\end{array}$ \\
\hline 1 & 9735.87 & 2850.00 & 3317.81 & 3568.06 & -974.26 & -212.59 \\
2 & 9756.76 & 2850.00 & 3465.05 & 3441.71 & -841.16 & -190.23 \\
3 & 9877.08 & 2850.00 & 3983.52 & 3043.55 & -1382.33 & -267.21 \\
4 & 9883.70 & 2850.00 & 4014.30 & 3019.40 & -1439.47 & -270.07 \\
5 & 9904.92 & 2850.00 & 4112.83 & 2942.10 & -1622.37 & -279.23 \\
6 & 9944.51 & 2850.00 & 4296.64 & 2797.87 & -1963.60 & -296.29 \\
7 & 10097.23 & 2850.00 & 4232.55 & 3014.68 & -1733.61 & -845.44 \\
Lambdas & & & & & 0.093 \\
(Weights) & & & & & 0.114 \\
1 & 0.048 & 0.7 & 0.02 & 0.065 & 0.074 & 0.079 \\
2 & 0.026 & 0.717 & 0.002 & 0.053 & 0.088 & 0.082 \\
3 & 0.029 & 0.725 & 0.002 & 0.087 & 0.078 & 0.078 \\
4 & 0.017 & 0.731 & 0.018 & 0.047 & 0.105 & 0.113 \\
5 & 0.012 & 0.702 & 0.019 & 0.087 & 0.102 & 0.1 \\
6 & 0.014 & 0.694 & 0.024 & 0.053 & 0.102 & 0.066 \\
7 & 0.018 & 0.733 & 0.022 & 0.061 & & \\
\hline
\end{tabular}

Assuming that management prefers result 2 in Table 6, which is simply the criterion vector, we can then obtain the values for the variables/actionable items using the inverse image of the criterion vectors. These results are shown in Table 2.

The purpose of this illustration is to show how many decision points are possible throughout the search process and the degrees of freedom which are available to management at each stage. Had we chosen a different solution from Table 3 after the first iteration we would have seen different results in Tables 4 through 6 . The illustration highlights the power of involving management in the search process, since they are in the best position to view results scenarios. It also highlights the simplicity of the process for management. They are not tasked with learning the rigorous mathematical underpinnings of the MOLP search process. They can instead focus in the space they understand (results and goals) and set policies based on their preferences.

\section{Conclusion}

Accounting managers face many budget problems that are too complex to solve effectively without tools to support their process. Problems that have multiple conflicting objectives and numerous legal, economic, and managerial constraints fall into this category. While there are other generally accepted methods of optimizing multiple objectives (such as goal programming), they do not involve the managers in the process. The Combined Tchebycheff/Aspiration Interactive method we illustrate allows management to drive the budget process by searching through potential solutions and narrowing in on an acceptable set of objective results. We illustrate the effectiveness of this method by creating a simplified transfer pricing problem for a MNE.

MNEs would like to manage transfer prices using an array of objectives to take advantage of global market imperfections. This is one of the most difficult problems faced by MNE management accountants. The MOLP search process helps management find a set of transfer prices that can satisfy a set of conflicting objectives. This method is capable of incorporating a wide variety of objectives and constraints found to be important to management as they search for the best set of transfer prices. Management is only required to understand its desired outputs and the tradeoffs between those outputs. The iterative search process is illustrated to show how the mathematical precision of multiple objective linear programming can structure a transfer pricing problem and be applied in a feasible manner bya non-mathematician manager.

Prior multiple objective transfer pricing research tends to collapse multiple objectives into linear programming formulations by weighting those objectives a priori (before management is given feedback on what is acceptable 
and what tradeoffs are possible). The search procedure advocated here using the structure of MOLP does not require a priori weights to be assigned to the objectives. In contrast it: (1)considers all the objectives simultaneously; (2) allows all feasible solutions to be considered; (3) presents trade-offs among conflicting objectives to be assessed; (4) allows weights to be inferred from managements' preferences in the context of the problem, and (5) allows an optimal solution to be selected based on management's often ill-defined utility function. Thus, the results are driven by managers' utility preferences, which are unspecified a priori, among competing objectives.

While not illustrated here, MOLP can also be used as a basis for negotiation among division managers as it lays out all the tradeoffs between objectives so that the consequences of each possible solution can be assessed. Likewise, management accountants could use MOLP as a "what-if" model to assess the consequences of various transfer pricing strategies in managing their global supply chain.

\section{References}

Al-Eryani, M. F., Alam, P., \& Akhter, S. H. (1990). Transfer pricing determinants of U.S. multinationals. Journal of International Business Studies, 21(3), 490-25. http://dx.doi.org/10.1057/palgrave.jibs.8490826

Balachandran, K. R., \& Steuer, R. E. (1982). An Interactive Model for the CPA Firm Audit Staff Planning Problem with Multiple Objectives. The Accounting Review, 57(1), 125-140.

Baldenius, T., Melumad, N. D., \& Reichelstein, S. (2004). Integrating Managerial and Tax Objectives in Transfer Pricing. The Accounting Review, 79(3), 591-615. http://dx.doi.org/10.2308/accr.2004.79.3.591

Borkowski, S. C. (1996). An Analysis (Meta- and Otherwise) of Multinational transfer Pricing Research. The International Journal of Accounting, 31(1), 39-53. http://dx.doi.org/10.1016/S0020-7063(96)90012-6

Burns, J. O. (1980). Transfer Pricing Decisions in U. S. Multinational Corporations. Journal of International Business Studies, 10, 23-39. http://dx.doi.org/10.1057/palgrave.jibs.8490603

Chan, K. H., Lo, A. W., \& Mo, P. L. (2006). Managerial Autonomy and Tax Compliance: An Empirical Study on International Transfer Pricing. The Journal of the American Taxation Association, 28, 1-22. http://dx.doi.org/10.2308/jata.2006.28.2.1

Cools, M., \& Emmanuel, C. R. (2007). Transfer pricing: The implications of fiscal compliance. In C. S. Chapman, A. G. Hopwood, \& M. D. Shields (Eds.), Handbook of management accounting research (Vol. 2, pp. 573-585). Amsterdam: Elsevier. http://dx.doi.org/10.1016/S1751-3243(06)02005-0

Cools, M., \& Slagmulder, R. (2009). Tax-compliant Transfer Pricing and Responsibility Accounting. Journal of Management Accounting Research, 21, 151-178. http://dx.doi.org/10.2308/jmar.2009.21.1.151

Cravens, K. (1992). A Comparative Investigation of Transfer Pricing Practices in an International Environment. Unpublished doctoral dissertation, Department of Accounting, Texas A \& M University.

Doupnik, T. S., \& Perera, H. B. (2009). International Accounting. New York, NY: McGraw Hill/Irwin.

Einhorn, H., \& Hogarth, R. (1981). Behavioral Decision Theory: Processes of Judgment and Choice. Journal of Accounting Research, 19(1), 1-31. http://dx.doi.org/10.2307/2490959

Elam, R., \& Henaidy, H. (1981). Transfer pricing for the multinational corporation. International Journal of Accounting, 49-66.

Ernst \& Young. (2007). Precision under pressure: Global transfer pricing survey 2007-2008. Retrieved from http://www.ey.com/-transferpricing-survey

Geoffrion, A. M., Dyer, J. S., \& Feinberg, A. (1972). An Interactive Approach for Multiple Criterion Optimization with an Application to the Operation of an Academic Department. Management Science, 19, 357-358. http://dx.doi.org/10.1287/mnsc.19.4.357

Goetschalckx, M., Vidal, C. J., \& Dogan, K. (2002). Modeling and design of global logistics systems: A review of integrated strategic and tactical models and design algorithms. European Journal of Operational Research, 143, 1-18. http://dx.doi.org/10.1016/S0377-2217(02)00142-X

Gox, R. F., \& Schiller, U. (2007). An Economic Perspective on Transfer Pricing. In C. S. Chapman, A. G. Hopwood, \& M. D. Shields (Eds.), Handbook of management accounting research (Vol. 2, pp. 673). Amsterda: Elsevier.

Johnson, W., \& Kirsch, R. (1991). International Transfer Pricing and Decision Making in the United States Multinationals. International Journal of Management, 89(2), 554-561. 
Kim, S. H., \& Miller, S. W. (1979). Constituents of the international transfer-pricing decision. Columbia Journal of World Business, 15, 69-77.

Lecraw, D. (1985). Some Evidence on Transfer Pricing by Multinational Corporations. In A. Rugman \& L. Eden (Eds.), Multinationals and Transfer Pricing. New York, St. Martin Press.

Leitch, R. A., \& Barrett, K. S. (1992). Multinational Transfer Pricing: Objectives and Constraints. Journal of Accounting Literature, 11, 47-92.

Leitch, R. A., Steuer, R. E., \& Godfrey, J. T. (1995). A Search Process for Multiple-Objective Management Accounting Problems: A Budget Illustration. Journal of Management Accounting Research, 7, 87-121.

Lin, T. W., \& O'Leary, D. E. (1993). Goal Programming Applications in Financial Management. Advances in Mathematical Programming and Financial Planning, 3, 211-229.

Morse, J. N. (1978). A Theory of Naïve Weights. Lecture Notes in Economics and Mathematical Systems, 155, 384-401. http://dx.doi.org/10.1007/978-3-642-46368-6_19

OECD. (2001). Transfer Pricing Guidelines for Multinational Enterprises and Tax Administrations. Paris OECD.

OECD. (2009). Transfer Pricing Guidelines for Multinational Enterprises and Tax Administrations, Paris OECD.

Perron, S., Hansen, P., Le Digabel, S., \& Mladenovic, N. (2010). Exact and heuristic solutions of the global supply chain problem with transfer pricing. European Journal of Operational Research, 202, 864-879. http://dx.doi.org/10.1016/j.ejor.2009.06.018

Ragsdale, C. (2001). Spreadsheet Modeling and Decision Analysis. SouthWestern-Cengage Learning, Mason, $\mathrm{OH}$.

Smith, M. (2002a). Ex Ante and Ex Post Discretion over Arm's Length Transfer Prices. The Accounting Review, 77(1), 161-184. http://dx.doi.org/10.2308/accr.2002.77.1.161

Smith, M. (2002b). Tax and Incentive Trade-Offs in Multinational Transfer Pricing. Journal of Accounting, Auditing and Finance, 209-236.

Steuer R. E., \& Choo, E. U. (1983). An Interactive Weighted Tchebycheff Procedure for Multiple Objective Programming. Mathematical Programming, 26, 326-344. http://dx.doi.org/10.1007/BF02591870

Steuer, R. E. (1986). Multiple criteria optimization: Theory, Computation, and Application. NY, Wiley.

Steuer, R. E. (2001). An Overview in Graphs of Multiple Objective Programming. Lecture Notes in Computer Science, 41-51. http://dx.doi.org/10.1007/3-540-44719-9_3

Steuer, R. E. (2006). ADBASE: A Multiple Objective Linear Programming Solver for Efficient Extreme Points and Unbounded Efficient Edges. Part I: Users Manual. Terry College of Business, University of Georgia.

Steuer, R. E., Silverman, J., \& Whisman, A. W. (1993). A Combined Tchebycheff/Aspiration Criterion Vector Interactive Multiobjective Programming Procedure. Management Science, 39(10). http://dx.doi.org/10.1287/mnsc.39.10.1255

Tang, R. Y. W. (1982). Environment variables of multinational transfer pricing: A U.K. perspective. Journal of $\begin{array}{llll}\text { Business Finance } \& \text { Accounting, } & \text { 9(Summer), }\end{array}$ http://dx.doi.org/10.1111/j.1468-5957.1982.tb00984.x

Tang, R. Y. W. (1992). Transfer pricing in the 1990s. Management Accounting, 22-26.

Vidal, C. J., \& Goetschalckx, M. (2001). A global supply chain model with transfer pricing and transportation cost allocation. European Journal of Operational Research, 129, 134-158. http://dx.doi.org/10.1016/S0377-2217(99)00431-2

Villegas, F., \& Ouenniche, J. (2008). A general unconstrained model for transfer pricing in multinational supply chains. European Journal of Operational Research, 187, 829-856. http://dx.doi.org/10.1016/j.ejor.2006.04.048

Wierzbicki, A. P. (1980). The use reference objectives in multiobjective optimization. Lecture Notes in Economics and Mathematical Systems, 177, 468-486. http://dx.doi.org/10.1007/978-3-642-48782-8_32

Wierzbicki, A. P. (1986). On the completeness and constructiveness of parametric characterizations to vector optimization problems. OR Spektrum, 8, 73-87. http://dx.doi.org/10.1007/BF01719738 
Zeleny, M. (1983). Multiple Criteria Decision Making. New York, NY: McGraw Hill.

Zionts, S., \& Wallenius, J. (1976). An Interactive Programming Method for Solving the Multiple Criteria Problem. Management Science, 22(6), 652-663. http://dx.doi.org/10.1287/mnsc.22.6.652

\section{Notes}

Note 1 . If the manager knew the utility for the individual objectives then $\mathrm{s} /$ he would be able to weight the multiple objectives, effectively collapsing them into a single objective linear program (as is done in goal programming).

Note 2. Mathematical programming models may include some transfer pricing objectives indirectly through constraints such as the model developed by Vidal and Goetschalckx (2001), reviewed in Goetschalckx et al. (2002), and extended in Perron et al., (2010), but they do not explicitly consider multiple objectives.

Note 3. Weights may be better derived interactively throughout a decision-support process that enables management to receive feedback from each iteration in the search process, allowing them to probe new combinations of objectives rather than using pre-determined weights (e.g., Morse 1978; Zeleny 1983; and Steuer 1986).

Note 4. Management can then test the feasibility of objectives given the transfer pricing environment, rather than simply relying on a mathematical program to present feasible alternatives or pairwise trade-offs as with some models (e.g. Geoffrion et al. 1972).

Note 5. See Ernst and Young (2007) for a comprehensive survey of MNE transfer pricing regulations by country.

Note 6. Other factors such as, import restrictions, currency regulations, exchange controls and Joint venture restrictions to control capital outflow, while not considered here could be modeled (Kim \& Miller 1979; Al-Eryani et. al. 1990 and Borkowski 1996).

Note 7. We do not illustrate the comparable uncontrolled price method (CUP). There are also other methods like the profit split and the transactional net margin methodswhich are acceptable, assuming CUP, CP and RPM are not feasible. For a full review of acceptable methods see OECD (2001, 2009). See Doupnik and Perera (2009) for how these are used.

Note 8. Indeed The US Treasury Even Has What They Call An "Arms Length" Range (U.S. Treasury Sec. 1.482-1).

Note 9. As Cools and Emmanuel (2007) summarize and APA's apparently consider, the revised OECD rules explicitly justify, with extensive documentation, consideration of production activities, assets and risks and conclude that a transfer price should be based on sound business grounds. While the fundamental principle of OECD guidelines is that a transfer price should be "that which would have been agreed upon between two independent firms for comparable transactions in comparable circumstances," (Gox \& Schiller 2007 pg. 690) the qualifications above make it clear that MNEs have substantial leeway in determining transfer prices( due to the fact that comparable transactions are not easily identified except in perfectly competitive markets).

Note 10. Also see Borkowski (1996), Vidal and Goetschalckx (2001), Goetschalckx et al. (2002), Villegas and Ouenniche (2008) and Doupnik \& Perera (2009).

Note 11. See Leitch et al. (1995) for an example where a similar method was used in a multi-objective budget model. The procedure used in this paper involves a combination of ADBASE (Steuer 2006) and Excel Solver.

Note 12. Extreme points are computed using Adbase (Steuer, 2006).

Note 13. Technically we use Archimedian goal programming where we assign weights (the default shown here of equal weights) and minimize the deviation from goals using these weights. Alternatively, a Lexicographic approach could be used where goals are prioritized and the solution procedure searches for a solution based on this priority seeing to minimize the deviations from the goals with the highest priority first and so on. See Leitch et al (1995) for a discussion of these methods in a managerial accounting setting.

Note 14. This is not to say that through many trials a reasonable weights cannot be derived through goal programming, but it would likely be a long and arduous process.

Note 15. Solver is used in Excel to calculate 2.4. The model is set up as shown in Figure MOLP 1. 


\section{Copyrights}

Copyright for this article is retained by the author(s), with first publication rights granted to the journal.

This is an open-access article distributed under the terms and conditions of the Creative Commons Attribution license (http://creativecommons.org/licenses/by/3.0/). 